\title{
Prototype Design of Landslide Early Detection System Using LoRa and IoT
}

\author{
Ahmad Taqwa ${ }^{1, *}$ Mohammad Fadhli ${ }^{1}$ Sopian Soim ${ }^{1}$ Ade Silvia Handayani ${ }^{1}$ Suroso ${ }^{1}$ \\ ${ }^{1}$ Politeknik Negeri Sriwijaya \\ "Corresponding author. Email: a_taqwa@yahoo.com
}

\begin{abstract}
This paper proposes a simple and low-cost landslide early detection system design. This system uses two sensors, namely the HC-SR04 ultrasonic sensor, to detect the soil movement and the YL-69 soil moisture sensor to detect soil moisture levels. Sensor data is processed using Arduino Uno. The soil movement and soil moisture data are sent to the receiving node using the LoRa communication system so that residents around locations with the potential for landslides can access data from the sensor nodes for free. This system is also equipped with an IoT system by using Thingspeak as an IoT platform. Based on the design and testing results, the LoRa system can work well at 250 meters in the channel with many buildings and trees. This research also designs an application to access sensor data via the Thingspeak web server using an Android device.
\end{abstract}

Keywords: Landslide, LoRa, IoT

\section{INTRODUCTION}

The Indonesian region has a tropical climate with high rainfall. The high rainfall increases soil mass to cause the slope surface to collapse, eventually becoming a landslide disaster. Landslides have resulted in various losses, such as material losses and claiming lives.

The fatalities due to landslides are difficult to avoid because the collapse of the land is very fast, so residents around the landslide location cannot save themselves. Research [1] shows that landslides' land displacement speed can reach $13 \mathrm{~m} / \mathrm{s}$ at a rating of $33.3 \mathrm{~m}$ with a maximum height of 95.2 masl. To increase the chances of surviving from the debris of soil material, residents in landslide-prone areas should always observe that disaster's signs.

Several studies have produced electronic instrument designs that can observe and detect signs of landslides using various methods. Fandi et al. [2] made a landslide detector using a sliding potentiometer and soil moisture sensor to detect the soil movement and soil moisture. ATMega328 microcontroller is used as a centre for processing information derived from sensors. This tool can detect landslide potentials well and can display landslide potential data through the website. Rihab et al. [5] designed a landslide detection system using four sensors: capacitive accelerometer, angular rate sensor, magnetometer, and pressure sensor. This landslide detection uses a LoRa-based wireless sensor network system so that sensor data can be sent wirelessly.

In this research, we combine the early detection of landslides signs in research [2] and [3] to propose a simple and low-cost prototype design for monitoring and detecting landslide potentials. We adopt sensor system from [1], which detects based on soil movement and soil moisture. The soil movement is detected with an HC-SR04 ultrasonic sensor, and soil moisture is detected with the YL-69 soil moisture sensor. Both sensors are expected to be able to read landslide potentials accurately at a low cost. The communication system for landslide early detection in this research is partially adopted from [3], which uses the LoRa communication system so that the sensor data can be accessed without internet connection by the resident around the sensor. To be accessible from anywhere, especially for relevant stakeholders, this landslide detection system is also equipped with an IoT system that can be accessed online via a computer or an Android device.

\section{LANDSLIDE WARNING SIGNS}

Knowledge about landslide signs is needed to determine the type of sensor to be used. Some of the signs of landslides are as follows [6]: 
a. Cracks in building or ground walls.

b. The collapse of the building part and soil on the slopes.

c. The occurrence of swelling on the slope cliffs or slope reinforcing construction walls.

d. Sloping of trees or poles on a slope.

e. The sudden appearance of water seepage on slopes.

f. The springs on the slopes became cloudy suddenly.

g. The water level of the river rose suddenly.

h. The collapse of large pieces of soil.

The factors that can cause landslides are as follows [6]:

a. Increased slope angle due to new construction or river erosion.

b. Increased water content caused by heavy rains or rising groundwater.

c. Reduced number of trees resulting in weakening of soil particles.

d. Changes in slope materials due to weather conditions and natural processes.

e. Vibration due to earthquake, eruption, engine movement, etc.

f. Additional loads by rain, volcanic material, buildings, or seepage from irrigation.

\section{LORA (LONG RANGE)}

LoRa is a wireless communication technology that has low power, long-distance, and low bitrate. LoRa has a low bit rate and low power consumption, making it suitable for use as a communication platform for the Internet of Things (IoT) technology, which requires a long time resilience of energy sources. Internet of Things (IoT) technology has been applied in many research, such as in our previous research [4-5]. LoRa can send and receive signals up to $15 \mathrm{~km}$ in an open area [3]. Semtech developed the LoRa physical layer with the Chirp Spread Spectrum (CSS) modulation technique, which has a data rate of up to $50 \mathrm{Kbps}$. Several physical layer parameters that can be set on LoRa technology include bandwidth (BW), Spreading Factor (SF) and Code Rate (CR) [7].

LoRa operates in the ISM band 433-, 868- or 915 $\mathrm{MHz}$, depending on the region where this technology is used [8]. For Indonesia's territory, the Ministry of Communication and Information has set the frequency allowed for LoRa in the range $920-923 \mathrm{MHz}$ [9]. In addition to frequency usage, LoRa duty cycle must also comply with local government regulations. Duty cycle is the fraction between packet time on air and delay between packets sent by a node [8]. For Indonesia's territory, the maximum duty cycle allowed is $1 \%$. Time on air on a LoRa communication network can be calculated using the following equations [7]:

$\mathrm{T}_{\text {packet }}=\mathrm{T}_{\text {preanible }}+\mathrm{T}_{\text {payload }}$

Where $T_{\text {packet }}$ is the packet duration or time on-air, $T_{\text {preamble }}$ is the preamble duration and $T_{\text {payload }}$ is the payload duration. The preamble duration can be calculated using equation (2):

$T_{\text {preamble }}=\left(n_{\text {preamble }}+4.25\right) T_{\sigma}$

Where $n_{\text {preamble }}$ is the preamble length, and $T_{s}$ indicates the duration for one symbol, where this duration is:

$T_{s}=1 / R_{g}$

Where $R_{g}$ indicates the symbol rate. The symbol rate can be calculated based on the spreading factor (SF) value in equation (4) below:

$R_{s}=B W_{/} /^{s F}$

The payload duration can be calculated by equation (5):

$T_{\text {paylond }}=P L S y m b \times T_{g}$

Where PLSymb is the number of symbols contained in the payload, which can be calculated using equation (6):

$P L S y m b=8+$

$\max \left(\operatorname{coil}\left(\frac{B P L-4 S F+2 B+16 C R C-20 H}{4[S F-2 D E)}\right)(C R+\right.$

4). 0 )

PL shows the number of bytes in the payload, $\mathrm{H}$ indicates a header's presence in each packet; if there is a header, $\mathrm{H}$ is 0 , and if no header, it is 1 . DE is 1 if there is optimization at low data rate conditions, and it is 0 for the opposite condition.

\section{EXPERIMENTAL SETUP}

The landslide early detection system in this research consists of several hardware devices, namely sensor nodes, receiver nodes, and gateways. Sensor nodes are used to capture the potential sign of landslides in the form of soil movement and soil moisture. Experiments in this research carried out using two sensor nodes. The receiver node is used for receiving data from sensor nodes on the local network using LoRa transmission. The gateway device is used to forward sensor data to the internet network via the Thingspeak IoT platform to be accessed online via computers and android mobile devices. The overall network architecture can be seen in Figure 1. 


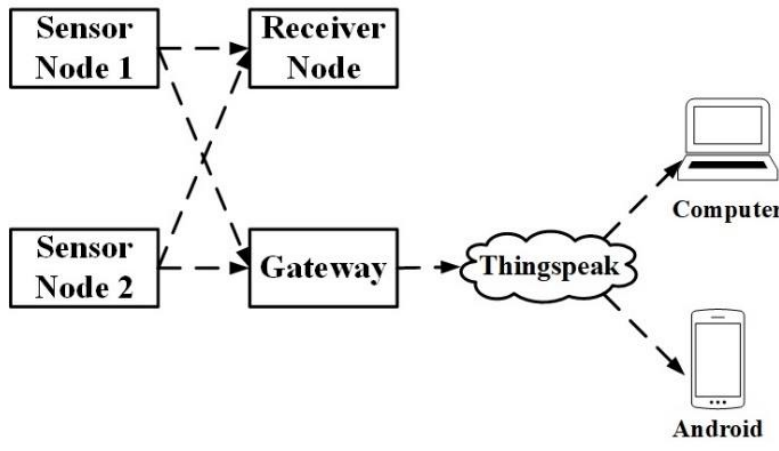

Figure 1 Network Architecture

\subsection{Sensor Node}

Sensor nodes measure two parameters of landslide signs, namely detecting soil movement and soil moisture level. The soil movement is detected using the HC-SR04 ultrasonic sensor, while soil moisture is measured in percentage values using the YL-69 soil moisture sensor. This sensor data is processed using the ATMega328P microcontroller found on the Arduino Uno. The sensor data is then transmitted wirelessly using the LoRa RFM95 chip. The hardware structure at the sensor node is shown in Figure 2.

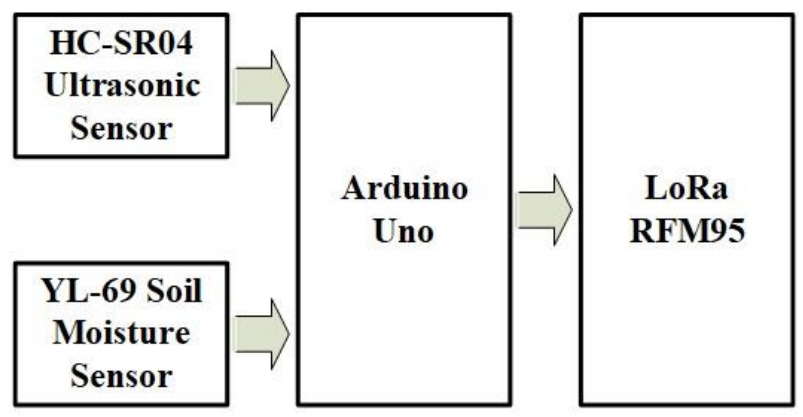

Figure 2 Sensor Node Architecture

For simulation, the soil movement with the potential for landslides was adopted based on research [10] by placing an obstacle on the slip surface facing the ultrasonic sensor. If the field is shifted, the distance between the obstacle and the ultrasonic sensor changes. This condition is illustrated in Figure 3.

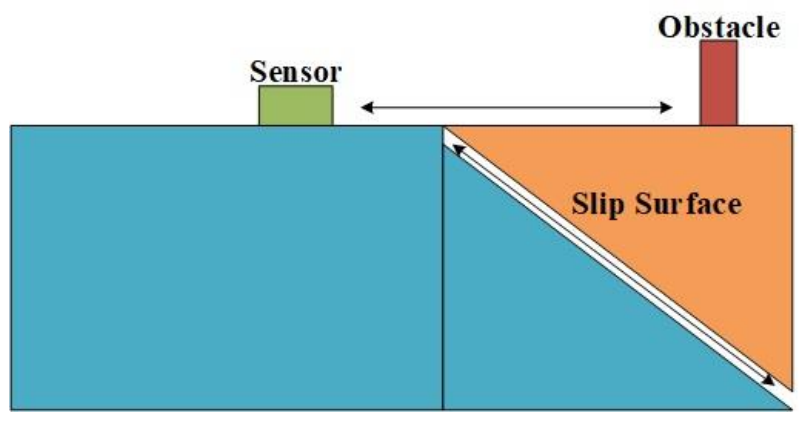

Figure 3 Simulation of Detecting Distance Shift
Each packet sent from the sensor node consists of obstacle distance shift and soil moisture data in the form of an integer and one string data that is used for separating the shift data from soil moisture so that the receiving node and gateway easily read it. In Arduino Uno, the integer is 2 bytes, while the string is 1 byte, so the amount of data sent is 5 bytes. This research uses SF 7, BW $125 \mathrm{KHz}, \mathrm{CR} 1$, preamble length 8, using an explicit header, and without CRC and low data rate optimization. Based on equation (1) to equation (6), each packet has a time on-air of $30.98 \mathrm{~ms}$. Based on packet time on-air, to comply with regulations, sensor data packets from each node are sent a maximum of one packet in 3 seconds.

Landslide potential status in this research is divided into three, namely "SAFE", "ALERT" and "DANGEROUS". To avoid signal collisions between nodes, the two sensor nodes send data at random intervals. In the "SAFE" status, packets are sent at intervals of 2 to 4 hours. In the status "ALERT", packets are sent at intervals of 15 to 20 minutes. While in the "DANGEROUS" status, the packets are sent between 3 to 5 seconds. If there is a change in status from "SAFE" to "ALERT" or to "DANGEROUS", the sensor node will immediately send the packet without waiting for a predetermined interval.

\subsection{Receiver Node}

The receiver node consists of the LoRa RFM95 chip, Arduino Uno, LCD, and buzzer. The connection between these hardware devices can be seen in Figure 4. LCD is used to display the distance shifts, percentage of soil moisture, and landslide potential status. The received soil moisture data is in the form of a 10-bit binary number so that if it is converted to decimal, it will have a range of value from 0 to 1023 . A value of 0 indicates maximum soil moisture of $100 \%$, and 1023 is a value of $0 \%$. Details of the criteria for landslide potential status can be seen in Table 1. The buzzer will sound dashed if it is in the "ALERT" status and will sound long if it is in the "DANGEROUS" status.

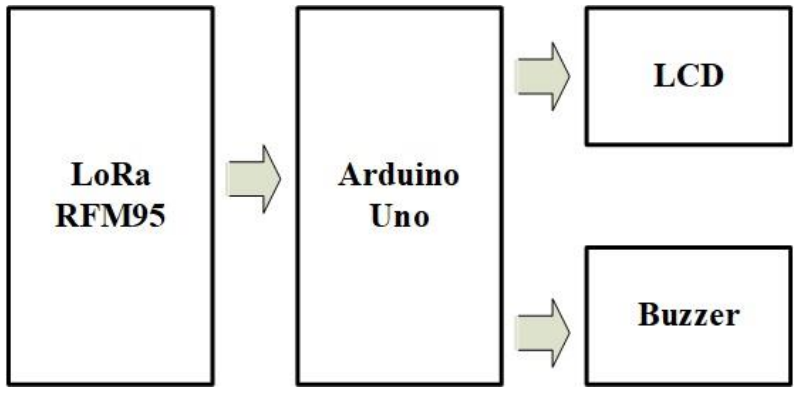

Figure 4 Receiver Node Architecture 
Table 1. Details of Landslide Potential Status

\begin{tabular}{|l|l|l|}
\hline \multicolumn{2}{|c|}{ Sensor Reading Results } & \multirow{2}{*}{ Status } \\
$\begin{array}{c}\text { Obstacle } \\
\text { Distance Shift }\end{array}$ & Soil Moisture & \\
\hline$<10 \mathrm{~cm}$ & $<50 \%$ & SAFE \\
\hline$<10 \mathrm{~cm}$ & $\geq 50 \%$ & ALERT \\
\hline$\geq 10 \mathrm{~cm}$ & $<50 \%$ & DANGEROUS \\
\hline$\geq 10 \mathrm{~cm}$ & $\geq 50 \%$ & DANGEROUS \\
\hline
\end{tabular}

\subsection{Gateway}

The gateway device consists of the LoRa RFM95 and NodeMCU v3 that uses the ESP32 module to connect to the WiFi network. Gateway device receives data from sensor nodes and forwards it to the Thingspeak webserver, so that landslide potential data can be accessed online via computers and Android devices. On a computer, sensor data can be accessed by entering the URL https://thingspeak.com/ in a web browser. This research also designs an application to access Thingspeak data via an Android device. This application was created using the MIT App Inventor.

\section{RESULT AND DISCUSSION}

After creating and integrating all the hardware and software, the next step is to test the system performance. Landslide conditions were simulated in a prototype box with an obstacle facing the ultrasonic sensor, as illustrated in Figure 3, and soil moisture sensor plugs into the soil in the box. The receiver node was placed at a distance of $250 \mathrm{~m}, 500 \mathrm{~m}$, and $750 \mathrm{~m}$ from the sensor nodes. The transmitter antenna height was $15 \mathrm{~m}$, while the receiver antenna height was $1 \mathrm{~m}$. In each measurement position, 30 data packets were sent. In order to know the maximum performance of the LoRa communication system, measurements were made in environments that have many obstacles, such as buildings and trees. At each measurement point, the sensor values, landslide potential status, RSSI, and the number of successfully received packets will be observed. The results at each measurement point can be seen in Table 2.

Table 2. Measurement Results

\begin{tabular}{|l|l|l|l|}
\hline \multirow{2}{*}{} & \multicolumn{3}{|c|}{ Distance } \\
\cline { 2 - 4 } & \multicolumn{1}{|c|}{$250 \mathrm{~m}$} & \multicolumn{1}{|c|}{$500 \mathrm{~m}$} & $750 \mathrm{~m}$ \\
\hline $\begin{array}{l}\text { Sent } \\
\text { Packets }\end{array}$ & $\begin{array}{l}30 \\
\text { Packets }\end{array}$ & 30 Packets & 30 Packets \\
\hline $\begin{array}{l}\text { Received } \\
\text { Packets }\end{array}$ & $\begin{array}{l}30 \\
\text { Packets }\end{array}$ & 22 Packets & 17 Packets \\
\hline $\begin{array}{l}\text { Average } \\
\text { RSSI }\end{array}$ & $-114 \mathrm{dBm}$ & $-115 \mathrm{dBm}$ & $-112 \mathrm{dBm}$ \\
\hline $\begin{array}{l}\text { Obstacle } \\
\text { shift }\end{array}$ & $0 \mathrm{~cm}$ & $0 \mathrm{~cm}$ & $11 \mathrm{~cm}$ \\
\hline $\begin{array}{l}\text { Soil } \\
\text { Moisture }\end{array}$ & $0 \%$ & $52 \%$ & $52 \%$ \\
\hline Status & SAFE & ALERT & DANGEROUS \\
\hline
\end{tabular}

The measurement results at $250 \mathrm{~m}$ show that all packets sent can be received by the receiving node. The average of received RSSI is $-114 \mathrm{dBm}$. At this point, the receiving node can detect obstacle distance shifts, soil moisture, and the potential landslide's status correctly. At a distance of $500 \mathrm{~m}, 22$ packets were successfully received. Of the 22 packets received, the average RSSI was $-115 \mathrm{dBm}$. At this distance, the received packets' quality has started to decline due to the increasing distance between the sensor node and the receiving node. However, the received sensor data can be identified correctly. At a distance of $750 \mathrm{~m}, 17$ packets were successfully received. Successfully received packets can still be correctly identified by the receiving node. At this distance, the average RSSI of received packets is $-112 \mathrm{dBm}$. Based on the results of this measurement, it can be seen that the RSSI at a distance of 750 meters is greater than at a distance of $500 \mathrm{~m}$ and $250 \mathrm{~m}$. This condition can be caused by a fading effect along the channel that the signal passes through, resulting in fluctuations in the received signal power.

The Android application to access sensor data from the Thingspeak web server has been designed successfully and works well. In this application, the obstacle distance shift and soil moisture are displayed from two sensor nodes. The appearance of this application can be seen in Figure 5.

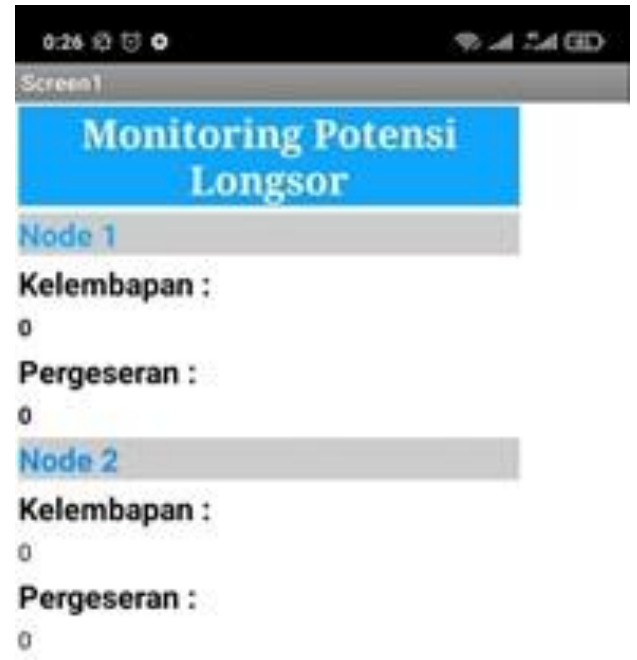

Figure 5 Android Application to Access Data from Thingspeak

\section{CONCLUSION}

The landslide detection system in this research has been able to work well in identifying landslide potential status according to predetermined criteria, using LoRa and IoT based communication system. Data packets sent by sensor nodes can be completely received at a distance of 250 meters with many obstructive objects such as buildings and trees. This range can be increased 
by adjusting the LoRa physical layer, such as coding rate, spreading factor and bandwidth. An Android-based application has also been running well to get sensor data from the Thingspeak web server.

\section{REFERENCES}

[1] M. Souisa, S. M. Sapulete, and S. O. Souisa, "Estimates of Velocity and Slide Travel Distance using ELM Sliding Approach," Barekeng J. Ilmu Mat. dan Terap., vol. 13, pp. 53-60, 2019.

[2] F. Aji Purnomo, N. Maulana Yoeseph, and G. Wijang Abisatya, "Landslide early warning system based on arduino with soil movement and humidity sensors," J. Phys. Conf. Ser., vol. 1153, no. $1, \quad 2019$, doi: 10.1088/17426596/1153/1/012034.

[3] R. F. Romdhane et al., "Wireless sensors network for landslides prevention," 2017 IEEE Int. Conf. Comput. Intell. Virtual Environ. Meas. Syst. Appl. CIVEMSA 2017 - Proc., pp. 222-227, 2017, doi: 10.1109/CIVEMSA.2017.7995330.

[4] N. L. Husni, Robi, E. Prihatini, Nurhaida, A. Silvia and Firdaus, "Garbage Monitoring and Warning System," 2019 International Conference on Electrical Engineering and Computer Science (ICECOS), Batam Island, Indonesia, 2019, pp. 171-175.

[5] A. S. Handayani, N. L. Husni, R. Permatasari and C. R. Sitompul, "Implementation of Multi Sensor Network as Air Monitoring Using IoT
Applications," 2019 34th International Technical Conference on Circuits/Systems, Computers and Communications (ITC-CSCC), JeJu, Korea (South), 2019, pp. 1-4.

[6] E. and usman syihab Yulaelawati, Mencerdasi Bencana. Jakarta: Grasindo, 2008.

[7] U. Noreen, A. Bounceur, and L. Clavier, "A study of LoRa low power and wide area network technology," Proc. - 3rd Int. Conf. Adv. Technol. Signal Image Process. ATSIP 2017, 2017, doi: 10.1109/ATSIP.2017.8075570.

[8] A. Augustin, J. Yi, T. Clausen, and W. M. Townsley, "A study of Lora: Long range \& low power networks for the internet of things," Sensors (Switzerland), vol. 16, no. 9, pp. 1-18, 2016, doi: 10.3390/s16091466.

[9] B. Siregar, H. F. Pratama and I. Jaya, "LPG Leak Detection System Using MQTT Protocol on LoRa Communication Module," 2020 4rd International Conference on Electrical, Telecommunication and Computer Engineering (ELTICOM), Medan, Indonesia, 2020, pp. 215-218, doi: 10.1109/ELTICOM50775.2020.9230518.

[10] S. Winanto, "Pembuatan Purwarupa Deteksi Pergeseran Tanah Berbasis Sensor Ultrasonik dan Mikrokontroler ATMega8535 Sebagai Potensi Aplikasi Sistem Peringatan Dini Tanah Longsor",Fakultas Matematika dan ilmu Pengetahuan Alam Universitas Sebelas Maret. Surakarta, 2011. 